\title{
The Prevalence and Correlates of Psychological Distress Among Undergraduate Students of Madda Walabu University, Ethiopia
}

\author{
Mulugeta Deribe Damota* \\ Department Psychology, Madda Walabu University, Bale Robe, Ethiopia, P.O.Box 247 \\ Emebet Girma Mekuria \\ Department Psychology, Kotebe Metropolitan University, Addis Ababa, Ethiopia \\ Alemihun Fenta Bitew \\ Department Special Needs and Inclusive Education, Debre Markos University, Debre Markos, , Ethiopia, \\ P.O.box 266
}

\begin{abstract}
The research is financed by Madda Walabu University
Abstract

Background: Students experiencing psychological problems, such as depression, anxiety, and stress, may face problems in managing their educational activities. Objective: The main purpose of this study was to examine the prevalence and correlates psychological distress among undergraduate Madda Walabu University students. Design: To achieve the objective cross-sectional research design was employed. Participants: Robe and Goba campus Madda Walabu University students were the aggregate populations of the study. The total number of population was 11,718 . Of 11718 students, 384 students were obtained by using proportionate stratified random sampling technique using colleges as strata. Instrument: DAS-S-depression, anxiety, stress scale, and questionnaires developed by the researchers to identify the determinant factors of depression, anxiety and stress were used to collect the data. Analysis: Quantitatively the collected data was analyzed by using percentage, Pearson correlation, and mean scores and standard deviation. Result and interpretation: Among the participants, $42.1 \%$ of the students were under depressive symptoms (13.0\% mild level; $12.8 \%$ moderate level; $9.9 \%$ severe level and the rest $5.5 \%$ under extremely severe level). In terms of anxiety, $48.1 \%$ of respondents score high anxiety level. Specifically, $6.3 \%$, were mild; $19 \%$ were a moderate level of anxiety; $15.1 \%$ and $8 \%$ of the students were under severe and extremely severe level respectively. $50.3 \%$ of the respondents were under stressful situations $(19.3 \%$ mild, $21.6 \%$ moderate; $7.8 \%$ severe and $1.6 \%$ were under extremely severe condition). The Pearson correlation results indicate that there is a significant negative correlation between depression, anxiety, and stress with academic achievement. Ten identified and accepted determinant factors that led students to were psychological distress were Substance use; chronic diseases; conflicts in terms of religious issues among students; conflicts in terms of racial issues among students; family functioning problem; poor study habits; excessive pressure or coercion from parents; excessive pressure or coercion from teachers; difficulty in making friend, and unfair assessment of instructors due difference in ethnicity. Recommendation: The results suggest that the early prevention of anxiety, depression, and stress is critical since, if left untreated, it can have serious consequences on students' future health and career possibilities.
\end{abstract}

Keywords: Academic achievement, Anxiety, Depression, Psychological distress, Stress

DOI: $10.7176 / \mathrm{JMPB} / 61-02$

Publication date: November $30^{\text {th }} 2019$

\section{Introduction}

Mental illness is a leading cause of disability worldwide, accounting for one-third of the years lost due to disability [1]. There has been increasing concern internationally about the mental health of university students and the impact unrecognized and untreated mental illness can have on impact individual students, the institution, and sometimes other students [2]. Researches are releasing the presence of psychological distress among undergraduate university students $[3,4]$.

Depression, anxiety, and stress are the most common, serious mental distress problems among student populations [5-7]. The prevalence of psychological distress among students reduces their self-esteem which might cause many problems at both personal and professional levels leading to dropout, impaired ability to work effectively, poor academic, disturbed relationship and suicide [8]. Another study by [9], has revealed that students' performance in University is affected by symptoms of Psychological distress. This may impair their academic achievement, lead to deterioration in relationships, marital problems and affect future employment [10]. The study by [11] reported a high prevalence of depression, anxiety, and stress, $27.1 \%, 47.1 \%$ and $27.0 \%$, respectively, among a group of Turkish university students. This is consistent with other studies which reported high rates of psychological morbidity among university students globally $[12,13]$.

When students failed to manage stressors, they may leave University education without finishing. According 
to [14], up to $60 \%$ of university students left University without finishing their degrees within first and second years due to inability to manage these psychological conditions especially to cope with stress. Study by [15] found that $50 \%$ of university students who consulted mental health service complained of difficulties in the study, anxiety, depression, and tension.

The presence of psychological distress associates with students' academic achievement which is the ultimate goal of students why they are at university. According to [16], many depressed individuals may be unable to perform well in academic life and may feel that they are not reaching the standard of performance set for them. As a result, they continuously feel disappointed and despairing. The same study [16] stated depressed individuals perceive things negatively and consider themselves as failures. This condition can definitely contribute too many serious problems in their academic life such as poor grades [16]. Study showed that there was an inverse relationship between academic achievement and depression [17-18]. The study found that students who experienced depression had a lower academic performance. University students face many problems such as separation from their families, entrance into a new environment and adaptation to educational standards causes a high level of depression [19]. When a student was too worried about their exams result, he/she would be depressed and this would affect their performance in education [20].

Students' performance is also affected by the presence of anxiety symptoms. Research demonstrated that students with a higher level of anxiety tend to obtain lower marks in their end-of-semester examination [21]. Study conducted by [22] has been conducted to see the correlation between anxiety and the influence of academic achievement, and found a student with high anxiety levels would have a lower academic achievement. Others expressed the opinion that the high level of anxiety will be associated with low academic performance [23, 24]. Similar result finds, a significant relationship between academic achievement and anxiety and found that a positive relationship between high degrees of academic achievement and low anxiety [25].

The third most common type of psychological distress among student is stress. The existence of stress according to [26] depends on the presence of the stressors. Stress is defined stressor as anything that challenges an individual's adaptability or stimulates an individual's body or mentality [27] and Academic stress is a product of a combination of academic-related demands that exceed the adaptive resources available to an individual [28].

Studies by [29 -31] demonstrated that student poor performance and stress are positively related. Here, in stress, there are contradictory issues. For example, a study by [32] on the effect of stress on students' performance in an Australian Dental school found little support for an association between increased stress scores and reduced academic performance among students. A study by [33] aimed to explore the association between stress levels and the academic performances shows that respondents with a high and severe stress level were observed to have higher cumulative grade point average (CGPA).

There is lack of research among Madda Walabu university students on the prevalence and magnitude of psychological distress and it relation with academic achievement. This may hinder our understanding about the psychological status of students at Madda Walabu University. This study focuses on the prevalence and magnitude of psychological distress among Madda Walabu University undergraduate students.

\section{Method and Materials \\ Description of the Study Area}

The study was conducted in Madda Walabu University. Madda Walabu University was established in 2006 in Bale zone, about 430 kilometers South East of the capital city of Ethiopia. In 2015 academic year the university has admitted about 13,000 students both at undergraduate and postgraduate levels by two campuses: Robe campus and Goba campus. Robe campus is the main campus of the University, which is found in Robe town. It encompasses most of the schools, students, and staff of the University. Goba campus is another campus of the university that encompasses the college of Medicine and Health Sciences and Global Referral Hospital of the University. Moreover, the university is conducting continuing education at its additional centers of Ginir and Dodola towns. The university has also established three research centers (Robe main center, Bidire, and Harawa-1 sub-center).

\section{Research design}

In this study, the researchers employed quantitative research

\section{Participants}

The total population of this study was all regular students attending their education in the two Campuses of Madda Walabu University. According to Madda Walabu registrar data, in 2015, 5859 students are attending their education from the second year and above. Of total students 4007 are males and 1776 are females. In order to select the respondents of the study, the researchers used a proportionately stratified sampling technique by using colleges and departments as strata. The number of the sample size for the study was determined based on the scientific sample size calculator developed by krejcie\& Morgan (1970). The researchers used this scientific sample size calculator because this technique was employed with a $95 \%$ confidence level and $5 \%$ degree of precisions. 
Totally, 384 undergraduate students were selected as a sample.

\section{Measures}

DASS-depression, anxiety, stress scale, and questionnaires developed by the researchers to identify the factors of psychological distress. Overall findings demonstrated that DASS scale had acceptable and fairly high validity and reliability scores and that it may be used as an efficient instrument in order to assess emotional states of university students. To check the reliability of DAS in this study pilot study was conducted. In addition, these tools were translated language and translated to Amharic by language expert the reliability index of the current study indicates all instruments are good.

The DASS is a 42-item questionnaire which includes three self-report scales designed to measure the negative emotional states of depression, anxiety, and stress. Each of the three scales contains 14 items, divided into subscales of 2-5 items with similar content. The depression scale items are 3, 5, 10, 13, 16, 17, 21, 24, 26, 31, 34, $37,38,42$; The anxiety scale items are $2,4,7,9,15,19,20,23,25,28,30,36,40,41$ and the stress scale items are $1,6,8,11,12,14,18,22,27,29,32,33,35$, and 39. Findings from discriminant validity showed that the DASS discriminates the normal and clinical population (Lovibond \& Lovibond, 1995).

Overall findings demonstrated that this scale had acceptable and fairly high validity and reliability scores and that it may be used as an efficient instrument in order to assess emotional states of university students.

\section{Data analysis}

After the data was collected it was analyzed qualitatively and quantitatively. Quantitatively, the collected data was inserted to SPSS 20 version and analyzed by using Percentage, Pearson correlation, Descriptive mean scores, and standard deviations.

\section{Ethical Consideration}

A letter introducing the objective of the study, and maintaining the confidentiality were attached as the cover page of the questionnaire. Participants gave informed consent for participation in the study.

\section{Result}

Demographic Results

Table 1: place of residence

\begin{tabular}{|l|l|l|l|}
\hline \multirow{4}{*}{ Pace of residence } & \multirow{3}{*}{ Urban } & Frequency & Percent (\%) \\
\cline { 2 - 4 } & Rural & 169 & 44.0 \\
\cline { 2 - 4 } & Total & 384 & 56.6 \\
\hline \multirow{3}{*}{ Sex of respondent } & Male & 213 & 100 \\
\cline { 2 - 4 } & Female & 171 & 55.5 \\
\cline { 2 - 4 } & Total & 384 & 44.5 \\
\hline
\end{tabular}

The above table 1 indicates the respondents' place of residence and their sex. From the respondents, $169(44.0 \%)$ of students are from urban and the rest $215(56.0 \%)$ are from rural whereas $213(55.55 \%)$ were males and the rest $171(44.5 \%)$ female

Table 2: Average Age of respondent

\begin{tabular}{|l|l|l|l|}
\hline Age of respondent & Mean & $\mathrm{N}$ & Std. Deviation \\
\hline Male & 21.5681 & 213 & 1.49569 \\
Female & 20.7135 & 171 & 1.07637 \\
Total & 21.1875 & 384 & 1.39047 \\
\hline
\end{tabular}

The average age of the respondents is 21.56 for males and 20.71 for females. The maximum age of the respondent is 23.06 for males and 21.78 for females. 
Descriptive results from main variables

Table 3: Mean score of depression, anxiety stress, and self-esteem with respect to sex

\begin{tabular}{lc|c|c|c}
\hline \multicolumn{2}{l}{ sex of respondents } & Depression & Anxiety & Stress \\
\hline \multirow{3}{*}{ Male } & Mean & 1.72 & 1.89 & 1.80 \\
& $\mathrm{~N}$ & 213 & 213 & 213 \\
& Std. Deviation & 1.20574 & 1.34888 & 1.07086 \\
\multirow{3}{*}{ Female } & Mean & 2.11 & 2.61 & 2.06 \\
& $\mathrm{~N}$ & 171 & 171 & 171 \\
& Std. Deviation & 1.30533 & 1.38965 & 1.07455 \\
\multirow{4}{*}{ Total } & Mean & 1.90 & 2.21 & 1.92 \\
& $\mathrm{~N}$ & 384 & 384 & 384 \\
& Std. Deviation & 1.26433 & 1.41202 & 1.07870 \\
\hline
\end{tabular}

Where 1- normal; 2 mild; 3-moderate; 4 -severe; 5 -extremely severe

The above table 3 depicted the average scores of depression, anxiety, stress with respect to their sex. As indicated the average depression for the male is $\mathrm{M}=1.72$ with $\mathrm{SD}=1.20$ and $\mathrm{M}=2.11$ with $\mathrm{SD}=1.30$. The average mean score of anxiety for male $\mathrm{M}=1.89, \mathrm{SD}=1.34$ whereas $\mathrm{M}=2.61, \mathrm{SD}=1.38$ for females. $\mathrm{M}=1.80, \mathrm{SD}=1.07$ and $\mathrm{M}=2.06, \mathrm{SD}=1.07$ were the average stress score for male and female participants respectively.

The prevalence of psychological distress among undergraduate students

Table 4: Prevalence of Depression

\begin{tabular}{|l|l|l|}
\hline Status of depression & Frequency & Percent \\
\hline Normal & 226 & $58.9 \%$ \\
\hline Mild & 50 & $13.0 \%$ \\
\hline Moderate & 49 & $12.8 \%$ \\
\hline Severe & 38 & $9.9 \%$ \\
\hline Extremely severe & 21 & $5.5 \%$ \\
\hline Total & 384 & 100.0 \\
\hline
\end{tabular}

As indicated in Table 4 above, 226(58.9\%) of the students were under normal condition. The rest $42.1 \%$ of the students were under depressive symptoms. From these students, 50(13.0\%) were under mild level; 49(12.8\%) were under moderate level; 38(9.9\%) were under severe level and the rest 21(5.5\%) under extremely severe level. Table 5: Magnitude /prevalence of anxiety

\begin{tabular}{|l|l|l|}
\hline Level of anxiety & Frequency & $\%$ \\
\hline Normal & 198 & $51.6 \%$ \\
\hline Mild & 24 & $6.3 \%$ \\
\hline Moderate & 73 & $19 \%$ \\
\hline Severe & 58 & $15.1 \%$ \\
\hline Extremely severe & 31 & $8 \%$ \\
\hline Total & 384 & 100 \\
\hline
\end{tabular}

As depicted in above table 5, the prevalence of anxiety among the respondent student is very high. From the respondents, only $198(51.6 \%)$ of students were under the normal condition whereas $48.1 \%$ of respondents were under anxiety level. Specifically, 24(6.3\%), were mild; 73(19.0) were under a moderate level of anxiety. The rest $58(15.1 \%)$, and $31(8.1 \%)$ of the students were under severe and extremely severe level respectively.

Table 6: The magnitude of stress

\begin{tabular}{|l|l|l|}
\hline Level of stress & Frequency & $\mathbf{\%}$ \\
\hline Normal & 191 & 49.7 \\
\hline Mild & 74 & 19.3 \\
\hline Moderate & 83 & 21.6 \\
\hline Severe & 30 & 7.8 \\
\hline Extremely severe & 6 & 1.6 \\
\hline Total & 384 & 100 \\
\hline
\end{tabular}

The above table 6 showed that, the magnitude of stressful conditions among respondents. As indicated $191(49.7 \%)$ of students were under normal condition and the rests score high in stressful condition (50.3\%). These were $74(19.3)$ mild, $83(21.6 \%)$ moderate; $30(7.8 \%)$ severe and $6(1.6 \%)$ were under extremely severe condition 
Correlates of psychological distress with academic achievement

Table 7: Pearson correlation of psychological distress (depression, anxiety, stress) and CGPA

\begin{tabular}{|l|l|l|l|l|}
\hline & CGPA & Depression & Sig. (2-tailed ) & N \\
\hline Depression & $-.618^{* *}$ & 1 & .000 & 384 \\
\hline Anxiety & $-.819 * *$ & $.779^{* *}$ & .000 & 384 \\
\hline Stress & $-.596 * *$ & $.743 * *$ & .000 & 384 \\
\hline
\end{tabular}

** Correlation is significant at the 0.01 level (2-tailed).

As indicated above Table 7 there is strong negative relationship between academic achievement and depression scores $\left[\mathrm{r}=-0.618^{* *}, \mathrm{n}=384, \mathrm{p}=0.000\right]$. This indicates when the level of depression score increases students' grade point decreases.

As also depicted above, there is strong negative significant relationship among students' academic achievement and anxiety score $\left[\mathrm{r}=-0.819^{* *}, \mathrm{n}=384, \mathrm{p}=0.000\right]$. This means that anxiety symptoms and students' academic achievement go in the opposite direction. As indicated above stress is also negatively correlated with students' academic achievement. Both variables has negative strong relationship $\left[r=-0.596^{* *}, \mathrm{n}=384, \mathrm{p}=0.000\right]$.

The study result showed in above table 7 , there is a strong positive significant correlation between the two variables (depression and anxiety) $\left[\mathrm{r}=0.778^{* *}, \mathrm{n}=384, \mathrm{p}=0.000\right]$.

There is also positive strong significant relationship between depression scores and stress scores $\left[\mathrm{r}=0.778^{* *}\right.$, $\mathrm{n}=384, \mathrm{p}=0.000]$. In both cases the longest the symptoms of stress and anxiety, the most probability of developing depression symptoms and vice versa.

Anxiety symptoms/scores and stress symptoms/scores has positive strong significant relationship $\left[\mathrm{r}=+0.719^{* *}\right.$, $\mathrm{n}=384, \mathrm{p}=0.000$ ]

1.1. Accepted Factors led undergraduate students to psychological distress among Madda Walabu University

Table 8: perceived factors among Students Based on Individual Scores to DAS

\begin{tabular}{|c|c|c|c|c|}
\hline & Factors & Mean & St.dev & Rank \\
\hline 1 & Having difficulty in dating & 1.5443 & 1.13022 & 17 \\
\hline 2 & Difficulty in making friends & 1.6250 & 1.05958 & 9 \\
\hline 3 & Conflicts in terms of religious issues among students & 1.8490 & 1.11393 & 3 \\
\hline 4 & Lack of coin for raw materials & 1.3646 & 1.07056 & 25 \\
\hline 5 & Worry about self-safety in the campus & 1.3437 & 1.10379 & 26 \\
\hline 6 & $\begin{array}{l}\text { Don't have an adequate recreational facility in terms of type and } \\
\text { quantity }\end{array}$ & 1.2474 & 1.06633 & 28 \\
\hline 7 & Conflicts in terms of racial issues among students & 1.7396 & 1.13795 & 4 \\
\hline 8 & Living room inconvenience to sleep anytime one wants & 1.2786 & 1.07570 & 27 \\
\hline 9 & Overcrowding in dormitory & 1.5234 & 1.54969 & 20 \\
\hline 10 & $\begin{array}{l}\text { New conditions that are stressful in the first exposure (like } \\
\text { presentation, }\end{array}$ & 1.5755 & .98793 & 14 \\
\hline 11 & Sleep deprivation & 1.5026 & 1.05711 & 22 \\
\hline 12 & School work increases (Eg. Excessive homework) & 1.5651 & 1.02243 & 16 \\
\hline 13 & Loneliness & 1.5651 & 1.20310 & 16 \\
\hline 14 & Homesickness & 1.1354 & 1.15277 & 30 \\
\hline 15 & Unfamiliarity of environment & 1.2214 & 1.03236 & 29 \\
\hline 16 & Excessive pressure or coercion from parents & 1.6615 & 1.13339 & 7 \\
\hline 17 & Excessive pressure or coercion from teachers & 1.6562 & 1.14329 & 8 \\
\hline 18 & Test-anxiety & 1.5078 & 1.13337 & 21 \\
\hline 19 & Deficits in social support & 1.5391 & 1.06868 & 18 \\
\hline 20 & curriculum and instruction & 1.4948 & 1.05957 & 23 \\
\hline 21 & Teamwork-related issues (Eg. Work with people you don't know) & 1.3854 & 1.70620 & 24 \\
\hline 22 & Unfair assessment of Instructors due difference in religion & 1.5703 & 1.13352 & 15 \\
\hline 23 & Unfair assessment of Instructors due difference in ethnicity & 1.5964 & 1.15217 & 10 \\
\hline 24 & Unfair assessment of Instructors due to gender & 1.5807 & 1.11891 & 13 \\
\hline 25 & gender violence & 1.5911 & 1.14122 & 12 \\
\hline 26 & Loss of loved one & 1.5937 & 1.17483 & 11 \\
\hline 27 & Family functioning problem & 1.7318 & 1.15776 & 5 \\
\hline 28 & Having inflexible rules about how one should behave & 1.5260 & 1.07880 & 19 \\
\hline 29 & Substance use-alcohol & 1.8620 & 1.18705 & 1 \\
\hline
\end{tabular}




\begin{tabular}{|l|l|l|l|l|}
\hline 30 & Chronic diseases & 1.8229 & 1.14937 & $\mathbf{2}$ \\
\hline 31 & Poor study habits & 1.7240 & 1.26071 & $\mathbf{6}$ \\
\hline
\end{tabular}

\section{N.B. Bolds are the leading 10 factors}

The above Table 8 presents the means and the standard deviations for 31 perceived sources of depression, anxiety, and stress and they are developed from academic factors, intrapersonal and self-factors; relationships, interpersonal, social factors; teaching quality, relations with teachers, support from teachers factors; and environmental, campus, administrative and transition factors.

From the table above 8 , the leading factor is health related /physical factors: substance abuse $(\mathrm{m}=1.86)$ and chronic illness $(\mathrm{M}=1.82)$ followed by relationship, interpersonal and social factors: conflicts in terms of religious issues among students $(\mathrm{M}=1.84)$

For also analysis of relationship, interpersonal and social factors: 'Conflicts in terms of ethnic issues among students" is the leading contributing factor for depression, anxiety and stress with a mean score of 1.73 followed by "family functioning problem" with a mean score of 1.73

An academic factor is the next leading factor "Poor study habits with a mean score of 1.72 by following 'Excessive pressure or coercion from parents" with a mean score of 1.66.

Hierarchically with their mean score, the leading factors are Excessive pressure or coercion from teachers $(\mathrm{m}=1.6562)$; Difficulty in making friends $(\mathrm{M}=1.6250)$; Unfair assessment of Instructors due difference in ethnicity $(\mathrm{M}=1.5964)$.

\section{Discussion}

In this part, the result of this study is discussed with the studies conducted in different setting by other scholars. The result showed $42.1 \%$ of the students were under depressive symptoms $(13.0 \%$ mild; $12.8 \%$ moderate; $9.9 \%$ severe $5.5 \%$ under an extremely severe level of depression. The result also showed $48.1 \%$ are under anxiety level $(6.3 \%$, mild; $19.0 \%$ moderate $15.1 \%$ severe, and $8.1 \%$ under extremely severe anxiety level). Concerning stress, $50.3 \%$ of respondents were under stressful conditions. From these individuals, $19.3 \%$ mild, and $21.6 \%$ moderate; $7.8 \%$ severe and $1.6 \%$ were under extremely severe condition.

In general, in our study, the prevalence level of depression and anxiety was detected among $42.1 \%$ and $48.1 \%$ of students. Similar studies conducted in Egypt universities reported higher figures; at Menoufiya University, the prevalence of depression and anxiety was $63.6 \%$ and $78.4 \%$ respectively [37]. Another study conducted in Mansoura University among medical students has reported lower figures; the prevalence of depressive and anxious symptoms was $28.3 \%$ and 21.2. Our findings are different to what is reported in other countries; in Pakistan, a prevalence of $70 \%$ anxiety and depression was reported among medical students [38].

On the other hand, our findings are similar to the study conducted by [39] have reported a prevalence of $43.89 \%$ of anxiety and depression among 482 medical students, In Beirut , 27.63\% and 69\% [40]); and in Iran was 33\% depression [41]. Similarly, a study conducted by [42] in a sample of university students across 10 universities in Hong Kong revealed that $41 \%$ of students experienced moderate levels of anxiety. Research result by [43] Reported that $54 \%$ of UK university students reached the sub threshold for anxiety.

The study conducted by[44] yielded a similar result that $41.9 \%$ of students in one of the Malaysian public institutions were found to have depression.

Our study result indicated, there is a negative strong significant relationship between depression, anxiety, and stress with students' academic achievement. Contrary to depression, anxiety, and stress have a strong positive significant relationship with each other. This result is similar with the study conducted by [22] research which stated student with high anxiety levels would have lower academic achievement among students. Others expressed the same opinion that the high level of anxiety will be associated with low academic performance [23, 24].

Similar result finds, a significant a positive relationship between academic achievement and anxiety [25], relationship between high degrees of academic achievement and low anxiety.

In terms of stress, for example, studies conducted by several researchers indicated that student poor performance and stress are positively related [29-31, 45]. Contrary, a study by [46] on the effect of stress on students' performance in an Australian Dental school found little support for an association between increased stress scores and reduced academic performance among students. Similarly, [47] examine the impact of stress factors on the academic performance of Pre-Diploma Science students at the University of Technology Malaysia. Here a lot of studies indicated contrasting ideas. The problem here is the severity level and an individual coping ability. For example, a study by [33] aimed to explore the association between stress levels and the academic performances shows that respondents with a high and severe stress level were observed to have higher cumulative grade point average (CGPA).

Another study conducted by [48]) found that stress affects students' academic achievement. Students complained of feeling stressed academically when it comes to facing exams and grade competition and having too much information to study yet insufficient time to master the knowledge. A similar finding revealed that stress is significantly correlated with poor academic performance in his study of business undergraduates [49]. 
Based on the research findings, depression is negatively related to the academic performance at similarly this research is consistent with [50] who claims that depression as one of the factors that contributed to academic performance.

\section{Conclusion}

The high rates of psychological distress among university students have major implications, not only with psychological morbidity, that will have adverse effects on students' health, development, educational attainment, and quality of life, but also the deteriorating influence on their own families, institutions and even other people's lives.

There is Statistical significance of DAS with academic achievement and self-esteem. Based on the result, there is a significant negative correlation between depression, anxiety, and stress with academic achievement. The higher depression, anxiety, and stress among students, the lower their academic achievement.

A list of ten major perceived factors of psychological distress among students were: Substance use; chronic diseases; conflicts in terms of religious issues among students; conflicts in terms of racial issues among students; family functioning problem; poor study habits; excessive pressure or coercion from parents; excessive pressure or coercion from teachers; difficulty in making friends; unfair assessment of instructors due difference in ethnicity.

\section{Recommendations}

Due to Academic and other related factors, university students might experience different types of psychological problems. So as to minimize this, life skill training is very important for students.

In addition, early screening is very important to provide appropriate treatment for students who are experiencing different types of psychological problems.

The presence of well-organized guidance and counseling is very crucial to prevent different psychological problems among students.

\section{Competing Interests}

The authors declare that they have no competing interests.

\section{ACKNOWLEDGEMENT}

The authors would like to acknowledge Madda Walabu University for it financial support.

\section{REFERENCES}

[1] World Health Organization. (2008). The global burden of disease: 2004 update. Geneva: WHO Press.

[2] Shuchman, M. (2007). Falling through the cracks-Virginia Tech and the restructuring of college mental health services. New England Journal of Medicine, 357(2), 105-110.

[3] Adlaf, E. M., Gliksman, L., Demers, A., \& Newton-Taylor, B. (2001). The prevalence of elevated Psychological distress among Canadian undergraduates: Findings from the 1998 Canadian campus survey. Journal of American College Health, 50, 67-72.

[4] Nerdrum, P., Rustøen, T., \& Rønnestad, M. H. (2006). Student psychological distress: A psychometric study of 1750 Norwegian 1st-year undergraduate students. Scandinavian Journal of Educational Research, 50(1), 95-109.

[5] Andrews B, Wilding JM. The relation of depression and anxiety to life-stress and achievement in

[6] Emslie GJ, Mayes TL, Ruberu M. Continuation and maintenance therapy of early-onset major depressive disorder. Paediatr Drugs. 2005;7:203-17. anxiety in nursing students. J Psychiatr Ment Health Nurs. 2004; 11:386-92.

[7] Saipanish R. Stress among medical students in a Thai medical school. Med Teach.2003;25(5):502-6

[8] Sharif F, Armitage P. The effect of psychological and educational counselling in reducing

[9] Dusselier, L.,Dunn, B., Wang, Y., Shelley, M. C.,\&Whalen, D.F.(2005).Personal, health, academic, and environmental predictors of stress for residence hall students. Journal of American College Health, 54, 1524

[10] Eisenberg, D., Gollust, S.E., Golberstein, E.,\& Hefner, J.L.(2007). Prevalence and correlates of depression, anxiety and suicidality among university students. American journal of orthopsychiatry, 77(4), 534-542.

[11] Bayram, N. and Bilgel, N. (2008) The Prevalence and Socio-Demographic Correlations of Depression, Anxiety and Stress among a Group of University Students. Social Psychiatry and Psychiatric Epidemiology, 43, 667-672.

[12] Adewuya A, Ola B, Olutayo O, Mapayi B, Oginni O (2006). Depression amongst Nigerian University students Prevalence and sociodemographic correlates. Psychiatr. Epidemiol. students. Br J Psychol. 2004;95:509-21.

[13] Ovuga E, Boardman J, Wasserman D (2006). Undergraduate student mental health at Makerere 
[14] Porter, O. F. (2007). Undergraduate completion and persistence at four-year colleges and Universities. National Institute of Independent Colleges and Universities

[15] Shamsuddin, K., et al., (2013). Correlates of depression, anxiety, and stress among Malaysian university students. Asian J. Psychiatry.

[16] Yasin, M.,\& Dzulkifli, A.M. (2010). The relationship between social support and academic achievement among students. International Journal of Business and Social Sciences.

[17] Stark, K. D. \& Brookman, C. S. (1994). Theory and family-school intervention. In Fine, J.M. \& Carlson, C. (Eds). The Handbook of Family-school Intervention: A System Perspective, Massachusetts: Allyn and Bacon.

[18] Zaid, Z. A., Chan, S. C., \& Ho, J. J. (2007). Emotional disorders among medical Students in a Malaysian private medical school. Singapore Medical Journal 48 (10): 895-899.

[19] Nasrin, I., (2010). The Development of Depression in Children and Adolescents. American Psychology. 53, 221-241.

[20] Achar, H. (2000). The Effect of Depression on Adolescent Academic Achievement. Southern Health Journal, 73, 871-900.

[21] Hamzah, M.H. (2007). Language Anxiety among First-Year Malay Students of the International Islamic College: An Investigation of L2 skills, Sources of anxiety, and L2 performance. A Master Dissertation in Human Science, IIUM, Malaysia.

[22] McCraty, R. (2007). When Anxiety Causes Your Brain to Jam, use Your Heart. Institute of Heart Math. HeartMath Research Center, Institute of HeartMath, Boulder Creek, CA.

[23] Luigi, M., Francesca, D., Maria, D.S., Eleonora, P., Valentina, G.D. and Benedetto, V. (2007). The Role of Anxiety Symptoms in School Performance in a Community Sample of Children and Adolescents. BMC Public Health 7 (347) doi: 10.1186/1471-2458-7-347.

[24] Sena, Whitaker, Lowe, Patricia, Lu, and Steven. 2007. Significant predictors of test anxiety Among students with and without learning disabilities. Journal of Learnin Disabilities, 40 (4), 360-376

[25] El-Anzi, F.O. 2005. Academic achievement and its relationship with anxiety, self-esteem, Optimism and pessimism in Kuwaiti students. Social behavior and Personality.

[26] Chen, K.L. 2009.“A Study of Stress Sources among College Students in Taiwan”, Journal of Academic and Business Ethics, 2(14): 1-8

[27] Volpe, J. F. (2000). A guide to effective stress management. Career and Technical Education, 48(10), 183188

[28] Kadapatti, M.G. and A.H.M. Vijayalaxmi, 2012."Stressors of Academic Stress-A Study of Pre- University Students", Indian Journal of Science Resources, 3(1): 171-175

[29] Sohail, N. 2013."Stress and Academic Performance among Medical Students", Journal of the College of Physicians and Surgeons, 23 (1): 67-71

[30] Wombie, L.P. (2005), "Impact of Stress Factors on College Students Academic Performance", Undergraduate Journal of Psychology, 16(1): 16-23.

[31] Taylor, M.F. and N.O. Owusi-Banana, 2010."Stress among Part-Time Business Students. A study in a Ghanaian University Campus", IFE Psychologia: An International Journal of Psychology, 18(1): 137-157.

[32] Lu, L., S.H. Kao, T.Chang, H.P. Wu, L. Cary and Cooper, 2008."Work/Family Demands, Work Flexibility, work/Family Conflict and Their Consequences at Work. A National Probability Sample in Taiwan", International Journal of Stress Management, 15(1):1-21.

[33] Siraj, H, H., A. Salam, R. Roslan, N.A. Hasan, T.H. Jin and M.N. Othman, 2014."Stress and its Association with the Academic Performance of Undergraduate Fourth Year Medical Students at University Kebangsaan Malaysia", the International Medical Journaln Malaysia, 13(1): 19-24

[34] Krejcie, R.V. and D.W. Morgan,1970. "Determining Sample Size for Research Activities", Educational and Psychological Measurement, 30(3): 607-610.

[35] Lovibond, H. S. \& Lovibond, P. F. (1995). Manual for Depression Anxiety Stress Scale.Sydney: Psychology Foundation.

[36] Abdallah AR, Gabr HM. Depression, anxiety, and stress among first-year medical students in an Egyptian public university. Int Res J Med Med Sci 2014;2(1):11-9.

[37] Khan MS, Mahmood S, Badshah A, Ali SU, Jamal Y. Prevalence of depression, anxiety and their associated factors among medical students in Karachi, Pakistan. J PakMed Assoc 2006;56:583-6.

[38] Jadoon NA, Yaqoob R, Raza A, Shehzad MA, Zeshan SC. Anxiety and depression among medical students: a cross-sectional study. JPMA J Pak Med Assoc. 2010;60(8):699-702.

[39] Mehanna Z, Richa S. Prevalence of anxiety and depressive disorders in medical students. A transversal study in medical students at the Saint-Joseph University of Beirut. Encephale 2006;32:976-82.

[40] Wong JG, Cheung EP, Chan KK, Ma KK, Tang SW (2006). The web-based survey of depression, anxiety, and stress in first-year tertiary education students in Hong Kong. J. Psychiatr.,40(9): 777-782.

[41] Webb E, Ashton C, Kelly P, Kamali F.Alcohol and drug use in UK university students. The Lancet. 1996; 
348(9032):922-925. PubMed | Google Scholar

[42] Sherina M. S., Lekhraj, R., \& Nadarajan, K. (2003). Prevalence of emotional Disorders among medical students in a Malaysian university. Asia PacFam Med, 2: 213-217.

[43] Hatcher, L.and J.S. Prus,1991."A Measure Of Academic Situational Constraints: Out-Of Class Circumstances That Inhibit College Student Development”, Educational Psychological Measurement, 51(4): 953-963.

[44] Sanders, A. \& Lushington, K. (2002) Effect of perceived stress on student performance in dental school. Journal of Dental Education, 66(1), 75(PDF) A comparison study of perceived stress and quality of life among Master of Pharmacy and non-pharmacy master's students.

[45] Rafidah, K., A. Azizah, M.D. Norzaid, S.C. Chong, M.I Salwani, and I.Noraini,2009."The Impact of Perceived Stress and Stress Factors on Academic Performance of Pre-Diploma Science Students: A Malaysian Study", International Journal of Scientific Research in Education, 2(1): 13-26.

[46] Elliot, A. J., Shell, M. M., Henry, K. B., \& Maeir, M. A. (2005). Achievement goals, performance contingencies, and performance attainment: An experimental test. Journal ofEducational Psychology, 97(4), 630-640.

[47] Bennett, R. (2003). Determinants of undergraduate student drop out rates in a university business studies department. Journal of Further and Higher Education, 27(2), 123-141.

[48] Zivin, J. (2009). Adolescents with Depressive Symptoms and Their Challenges with Learning in School. The Journal of School Nursing. 26(5), 377-39 